\title{
What Money Cannot Buy? Compassion in Healthcare: A Response to the Recent Commentaries
}

\section{Marianna Fotaki* \\ *Correspondence to: Marianna Fotaki, Email: marianna.fotaki@wbs.ac.uk Copyright: $\odot 2015$ by Kerman University of Medical Sciences \\ Citation: Fotaki M. What money cannot buy? compassion in healthcare: a response to the recent commentaries. Int J Health Policy Manag. 2015;4(12):873-874. doi:10.15171/ijhpm.2015.180 \\ Received: 20 September 2015, Accepted: 1 October 2015, ePublished: 2 October 2015}

$\mathrm{L}$ et me first start by thanking everyone who responded to my editorial entitled: 'Why and How is Compassion Necessary to Provide Good Quality Healthcare?' It is both a humbling and deeply gratifying experience, to receive so many thoughtful and valuable comments from colleagues whose work I know and respect. And it is in equal measure, rewarding and stimulating, to be able to read engaging and incisive responses from colleagues I have never met but whose writings inspire me. These are rare gifts to be cherished, and they remind me of my privileged position as a member of the virtual community where such a genuine exchange of ideas takes place. They help me to forward my thinking on issues about which I care deeply.

This brings me back to the topic of the editorial. When I wrote it, I was primarily motivated by my concern about the shifting values in healthcare under neoliberal ideology and the multiple ways in which it has colonized the public institutions that provide it. The application of consumerist market-based solutions in healthcare obscures the real issue of the threat of reduced availability of care when it becomes a private good rather than a needs-based, free and universally provided service as is likely to be the future of the National Health Service (NHS) in England. ${ }^{2}$ Such neoliberal ideology coexists with bureaucratic practices in the NHS: both are used to compel health professionals to act 'compassionately'. This introduces perverse incentives for health professionals to moderate their responses and manage their emotions in accordance with commercial or performance targets set by the organization ${ }^{3}$; self-preservation then often causes them to detach from their patients to avoid emotional burnout.

Indeed, my central premise is that we cannot commodify and instrumentalize care without doctors and nurses losing the altruistic motivation and capacity for compassion that attracts many to the caring professions. Such humanist and prosocial values flourish through the very act of giving freely, which emerges from relating to, and identification with, the other. In his Gift Relationship, Titmuss ${ }^{4}$ famously argues against introducing direct economic calculation in blood donation services. This is to avoid deterring many potential donors in addition to producing other undesirable social consequences such as the exploitation of the poor members of society and the commercialization of the human body. ${ }^{5}$ However, altruistic ideals and qualities of empathy appear to decrease among some medical students as they progress through their education and are increasingly exposed to heavy workloads and technical, non-humanist aspects of medicine. ${ }^{6}$

Harding ${ }^{7}$ captures well the contradictory demands that marketized healthcare places on health professionals, who are expected to act simultaneously as efficient automatons and as sentient humans who empathize with their patients. These conflicting expectations create an ambiguity in the subject that needs to be acknowledged since, as Kate Kenny reminds us drawing on Judith Butler's work, we desire conformity with influential social norms in order to exist socially, even if these norms might harm us. ${ }^{8}$ Even so, values and institutions are human creations that are closely intertwined with power and are open to contestation. ${ }^{9}$ Such values and norms benefit some while excluding many others ${ }^{10}$ but they can change and have been changing over time.

Leget $^{11}$ correctly argues that we need philosophies to help us deal better with the vulnerability of the human condition. However, my view is that an ethics of connectedness, coexistence and compassion towards the other, ${ }^{12}$ which is rooted in the corporeality of care, is equally important. There is no reason why we cannot collectively create systems that build on professionals' good will, and that foster the ethos of altruism that attracted them to this work in the first instance. This requires that we oppose and strive to diminish all societal forces that destroy the innate compassion in health professionals, ${ }^{13}$ and our own ability to empathize with vulnerability and weakness as citizens and social beings. But to do so we must first reject the neoliberal fallacy of disembedded autonomous individuals who are primarily driven by maximizing their own utility at the expense of the other. It also means that we as society need to care for health professionals and their emotional well-being rather than expect them to deal heroically with impossible contradictions or strive to change their 'organizational culture,' which is unlikely to yield any meaningful results on its own. ${ }^{14}$ We can achieve this by creating space for reflection and experiencesharing at work, ${ }^{15}$ but also more crucially, as Christos Lionis suggests, by turning the undergraduate medical education into a relational and interpersonal practice. Such a pedagogical approach will help restore the value of care and compassion as forces that bind us together, without which no society can sustain itself or survive in the long run.

Ethical issues

Not applicable.

Warwick Business School, University of Warwick, Coventry, UK 


\section{Competing interests}

Author declares that she has no competing interests.

Author's contribution

MF is the single author of the manuscript.

\section{References}

1. Fotaki M. Why and how is compassion necessary to provide good quality healthcare? Int $J$ Health Policy Manag. 2015;4(4):199201. doi:10.15171/ijhpm.2015.66

2. Greener I. Wolves and Big Yellow Taxis: how would be know if the NHS Is at Death's Door? Int J Health Policy Manag. 2015;4(10):687-689. doi:10.15171/ijhpm.2015.124

3. Gabriel Y. Beyond compassion: replacing a blame culture with proper emotional support and management: Comment on "Why and how is compassion necessary to provide good quality healthcare?" Int J Health Policy Manag. 2015;4(9):617-619. doi: 10.15171/ijhpm.2015.111

4. Titmuss R. The Gift Relationship. From Human Body to Social Policy. London: LSE Books; 1970/1997.

5. Pennings G. Demanding pure motives for donation: the moral acceptability of blood donations by haemochromatosis patients. J Med Ethics 2005;31:69-72. doi:10.1136/jme.2002.001271

6. Burks DJ, Kobus AM. The legacy of altruism in health care: the promotion of empathy, prosociality and humanism. Med Educ. 2012;46(3):317-325. doi:10.1111/j.1365-2923.2011.04159.x

7. Harding N. Why the critics of poor health service delivery are the causes of poor service delivery: a need to train the policymakers: Comment on "Why and how is compassion necessary to provide good quality healthcare?" Int $\mathrm{J}$ Health Policy Manag. 2015;4(9):633-634. doi:10.15171/ijhpm.2015.118

8. Kenny K. Healthcare and compassion: towards an awareness of intersubjective vulnerability: Comment on "Why and how is compassion necessary to provide good quality healthcare?" Int J Health Policy Manag. 2015;16;4(9):627-629. doi:10.15171/ ijhpm.2015.115

9. Mercer D. Imagined in policy, inscribed on bodies: defending an ethic of compassion in a political context: Comment on "Why and how is compassion necessary to provide good quality healthcare?" Int J Health Policy Manag. 2015;4(10):681-683. doi:10.15171/ijhpm.2015.125

10. Fotaki M, Prasad A. Questioning Neoliberal Capitalism and Economic Inequality in Business Schools. Academy of Management Learning \& Education 2015. http://amle.aom.org/ content/early/2015/09/17/amle.2014.0182.1.full.pdf

11. Leget $\mathrm{C}$. Why good quality care needs philosophy more than compassion: Comment on "Why and how is compassion necessary to provide good quality healthcare?" Int J Health Policy Manag. 2015;4(10):677-679. doi:10.15171/ijhpm.2015.122

12. Kenny K, Fotaki M. From Gendered Organizations to Compassionate Borderspaces: Reading Corporeal Ethics with Bracha Ettinger. Organization. 2015;22(2):183-199.

13. Lown BA. Compassion is a necessity and an individual and collective responsibility Comment on: "Why and how is compassion necessary to provide good quality healthcare?" Int J Health Policy Manag. 2015;4(9):613-614. doi:10.15171/ ijhpm.2015.110

14. Lionis C. Why and how is compassion necessary to provide good healthcare? Comments from an academic physician: Comment on "Why and how is compassion necessary to provide good quality healthcare." Int J Health Policy Manag. 2015; forthcoming. doi:10.15171/ijhpm.2015.132

15. Shea S. Is it possible to develop a compassionate organization? Comment on "Why and how is compassion necessary to provide good quality healthcare?" Int J Health Policy Manag. 2015; forthcoming. doi:10.15171/ijhpm.2015.119 